\title{
A Study of the Morphological Changes and the Growth Kinetics of the Oxides Formed by the High Temperature Oxidation of $\mathrm{Cu}-32.02 \% \mathrm{Zn}-2.30 \% \mathrm{~Pb}$ Brass
}

\author{
Aniedi E. Nyong ${ }^{a} *$ (1), Godwin Udoh ${ }^{a}$, Joachim J. Awaka-Ama ${ }^{a}$, Edet W. Nsi ${ }^{a}$, Pradeep K. Rohatgi ${ }^{b}$ \\ ${ }^{a}$ Akwa Ibom State University, Department of Chemistry, Materials Chemistry Research Unit, Nigeria. \\ ${ }^{b}$ University of Wisconsin-Milwaukee, Department of Materials Science and Engineering, Center for \\ Composite Research, USA.
}

Received: April 12, 2021; Revised: July 28, 2021; Accepted: September 18, 2021

\begin{abstract}
The high temperature oxidation of $\mathrm{Cu}-32.02 \% \mathrm{Zn}-2.30 \% \mathrm{~Pb}$ brass was carried in $\mathrm{N}_{2}-5 \mathrm{wt} . \% \mathrm{O}_{2}$ and $\mathrm{N}_{2}-12 \mathrm{wt} . \% \mathrm{O}_{2}$ atmospheres. The amounts of oxygen in the oxidizing atmospheres and the time of the oxidation affected the oxide morphologies and kinetics of the oxide growth. In the first hour of the oxidation at $650{ }^{\circ} \mathrm{C}$, oxide nanowires were noted. The average diameter, length and distance between the observed nanowires were $27 \pm 0.01 \mathrm{~nm}, 0.20 \pm 0.04 \mu \mathrm{m}$ and $0.20 \pm 0.04 \mu \mathrm{m}$ respectively for the samples oxidized in $\mathrm{N}_{2}-5 \mathrm{wt} . \% \mathrm{O}_{2}$ atmosphere and $102 \pm 23 \mathrm{~nm}, 0.36 \pm 0.24 \mu \mathrm{m}$ and $0.24 \pm 0.08 \mu \mathrm{m}$ respectively for the samples oxidized in $\mathrm{N}_{2}-12 \mathrm{wt} . \% \mathrm{O}_{2}$ atmosphere. The EDX and XRD analyses of the nanowires and the oxide granules confirmed $\mathrm{ZnO}$ nanowires and a continuous oxide layer of $\mathrm{ZnO}$. The $\mathrm{x}$-ray diffraction confirmed minor presence of $\mathrm{PbO}$. The oxide growth kinetics followed the linear oxide growth model, for the alloy samples that were thermally oxidized in $\mathrm{N}_{2}-5 \mathrm{wt} . \% \mathrm{O}_{2}$ atmposphere and parabolic growth model for those thermally oxidized in $\mathrm{N}_{2}-12 \mathrm{wt} . \% \mathrm{O}_{2}$ atmospheres respectively. The values of $6.8 \mu \mathrm{m} /$ hour and $23.03 \mu \mathrm{m} /$ (hour $^{1 / 2}$ were determined for growth constant $(k)$, based on the two models respectively.
\end{abstract}

Keywords: Thermal oxidation, growth kinetics, brass.

\section{Introduction}

Brass is an alloy that consist of mainly copper and zinc $^{1,2}$. Lead is often used as an alloying additive to ease the machining of brass and such brasses are referred to as leaded brasses ${ }^{3}$. Leaded brasses consist mostly of a two phase structure, namely the alpha and the beta phases, with the lead particles randomly distributed at the grain boundaries $s^{4,5}$. However, depending on the amount of zinc, brass as an alloy can exist with a single alpha-phase ${ }^{6}$.

Thermal oxidation has been used as a means of growing oxide nanostructures on the surfaces of metals and their alloys and several of such works are available in literature ${ }^{7-9}$. These oxide nanostructures are reported to exist in various forms such as nanowires, nanorods, nanoflakes, nanotubes, nanoneedle, nanorings, nanofibers and nanocombsetc ${ }^{10,11}$. The nature, form and type of these nanostructures have been found to be dependent on the oxidizing conditions such as time, temperature and pressure etc.

For instance, the effect of temperature on the morphology of the oxides formed through the thermal oxidation of some copper alloy has been elucidated in some recent publications ${ }^{12,13}$. Furthermore, the variation of the temperature of oxidation of copper $[\mathrm{Cu}(100)]$ thin films have shown same effects on the different morphological forms of the copper (I) oxide $\left(\mathrm{Cu}_{2} \mathrm{O}\right)$ formed; which included pyramids, nanorods, domes or terraced layered oxide structures. In the same vein, the influence of oxygen pressure on the morphology of zinc

*e-mail: aniedinyong@aksu.edu.ng oxide thin films formed during low temperature thermal oxidation has been studied ${ }^{14-16}$. The oxygen pressure, affected the morphology resulting in oxide forms such as whiskers, nanowires and cluster-like oxide grains.

Beyond the investigation into the various forms of nanostructures induced through thermal oxidation, the mechanism and the growth kinetics of these oxides in relationship with the various parameters of the thermal oxidation process have been studied. In this regards, the copper oxidation mechanism and purity effects were studied between a set of temperature of $350{ }^{\circ} \mathrm{C}$ to $1050{ }^{\circ} \mathrm{C}$. The oxidation kinetics at the set of temperatures studied followed the parabolic oxidation rate law. The predominanat oxide was the $\mathrm{Cu}_{2} \mathrm{O}$ scale that was confirmed to have formed from an outward diffusion of copper ions in the $\mathrm{Cu}_{2} \mathrm{O}^{17}$. Also some studies of the kinetics of the thermal oxidation of $\mathrm{Cu}-\mathrm{Zn}$ alloys in pure oxygen or in air at room and higher temperature have been the focus of studies in literature ${ }^{18,19}$

From the brief review it is clearly seen that the thermal oxidation conditions affect the morphology of the oxides formed by the metals and their alloys. Other parameters which have been showed to have an influence on the morphology and growth of oxides include the presence of water vapour and other gaseous additives to the oxidization atmosphere ${ }^{20}$.

This work is aimed at investigating the effect of the amount of oxygen and thermal oxidation time on the chemistry of the oxide scale, the morphology and the growth kinetics of the oxides formed on the high temperature thermal oxidation of $\mathrm{Cu}-32.05 \% \mathrm{Zn}-2.30 \% \mathrm{~Pb}$ brass. The $\mathrm{Cu}-32.05 \% \mathrm{Zn}-2.30 \%$ 
$\mathrm{Pb}$ brass is typical leaded copper alloy that has enormous use in plumbing and other industrial applications and is often exposed to high temperature conditions. Prior to now, such work has not been reported in literature for this range of leaded copper alloy.

\section{Materials and Method}

\subsection{Materials}

The $\mathrm{Cu}-32.02 \% \mathrm{Zn}-2.30 \% \mathrm{~Pb}$ brass used in the experiments was obtained from Grainger, USA. The $\mathrm{N}_{2}-\mathrm{O}_{2}$ gas mix grades used for the thermal oxidation were obtained from Praxair in Brookefield, USA and were used to set up the thermal oxidation atmospheres. These various $\mathrm{N}_{2}-\mathrm{O}_{2}$ gas mixtures grades used included the $\mathrm{N}_{2}-5$ wt. $\% \mathrm{O}_{2}$ and $\mathrm{N}_{2}-12$ wt. $\%$ $\mathrm{O}_{2}$ grade types.

\subsection{Method}

The samples of the $\mathrm{Cu}-32.02 \% \mathrm{Zn}-2.30 \% \mathrm{~Pb}$ brass were sectioned into smaller sizes with dimension of $2.0 \mathrm{x}$ $1.0 \times 0.5 \mathrm{~mm}$. These samples were then grounded and polished until fine and smooth surfaces were obtained. For the grinding and polishing procedure, the Buehler Metaserv 3000 model polishing machine, mounted with various grades of $\mathrm{SiC}$ paper was used. To ensure a very smooth and polished surface, a soft cloth immersed in 0.1 micron aluminum slurry was used, in the final step. The polished samples were then washed in distilled water in an ultrasonic bath, blown dry with compressed air and stored in an air-tight dessicator.

For the thermal oxidation in various atmospheres, a furnace with an inlet and an outlet for the flow of gas was used. The various gaseous mixtures of $\mathrm{N}_{2}-\mathrm{O}_{2}$ were flowed through the furnace, with the alloy samples inside the furnace chamber, at a controlled rate of 4.5 liters per minute for the set time of the thermal oxidation process. The temperature for the process was set at $650{ }^{\circ} \mathrm{C}$ and the timing was set for 1, 2 and 3 hours. After the set time, the samples were carefully retrived from the furnace and allowed to cool in an air-tight dessicator.

\section{Characterization}

The thermally oxidized alloy samples were characterized to determine the chemical composition of the oxide layer, the oxide morphology, the oxide granule sizes and the thickness of the oxide layer. To evaluate the surface morphology, the Hitachi-4800 scanning electron microscope (SEM) was used. Attached to the scanning electron microscope was the energy dispersive $\mathrm{x}$-ray probe that was used for the spot analyses to determine the chemistry of the various features on the oxidized surface layer of the alloy.

Beyond the surface morphological investigations, the SEM was equally used to evaluate the thickness of the various oxide layers. To estimate the thickness of the oxide layer, a side-view of the oxide layer was projected from which the thickness of the oxide layer was determined. In addition to the energy dispersive $\mathrm{x}$-ray, $\mathrm{x}$-ray diffraction analysis was also used to determine the chemical composition of the oxide layers. The x-ray diffraction analysis was achieved using the Scintag-2000 x-ray machine, at $2 \Theta$ range of $10^{\circ}-70^{\circ}$ at a continuous count rate of $2 \%$ min., with the $\mathrm{k}_{\alpha}-\mathrm{Cu}$ emission of $\lambda=1.54^{\circ} \mathrm{A}$.

\section{Results and Discussion}

The results of the thermal oxidation of the $\mathrm{Cu}-32.02 \%$ $\mathrm{Zn}-2.30 \% \mathrm{~Pb}$ brass in the $\mathrm{N}_{2}-\mathrm{O}_{2}$ gas mixtures at $650{ }^{\circ} \mathrm{C}$ are discussed in terms of the chemistry of the oxide layer, the effect of the amount of oxygen available for the thermal oxidation, the effect of time of the thermal oxidtion on the oxide morphology and the growth kinetics of the oxidae layer.

\subsection{The chemistry of the oxide layer}

An array of nanowires and other surface features noted through the observation of the oxide surface were further analysed using the energy dispersive $x$-ray probe. The energy dispersive x-ray appraisal of the surface nanowires formed from the thermal oxidation showed a preponderance of zinc and oxygen. This can be seen in Figure 1. In this case, the elemental composition, represented in weight percentage, consisted of $80.47 \mathrm{wt} . \%$ and $19.53 \mathrm{wt}$. \% for zinc and oxygen respectively. These values are in good agreement with the theoretically calculated weight percentages of $\mathrm{Zn}$ and $\mathrm{O}$ in
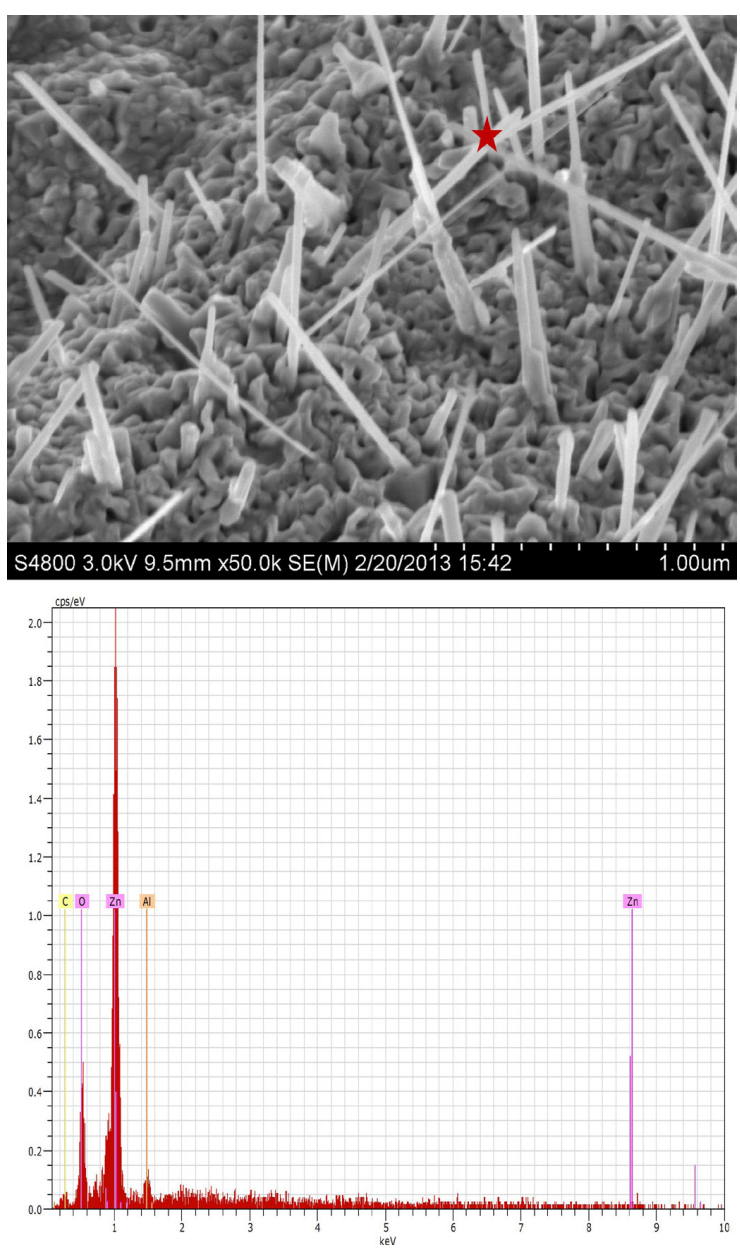

Figure 1. The EDX evaluation of the nanowires observed on the surfaces of the thermally oxidized $\mathrm{Cu}-32.02 \% \mathrm{Zn}-2.30 \% \mathrm{~Pb}$ alloy. 
ZnO; which are 80.33 wt.\% and 19.66 wt. \% respectively. To this end, the energy dispersive $\mathrm{x}$-ray appraisal of the nanowires confirmes them as $\mathrm{ZnO}$ nanowires.

The $\mathrm{x}$-ray diffraction peaks, as presented in Figure 2 ( $\mathrm{a}$ and b), showed a consistency in the composition of the oxides formed irrespective of the amount of the oxygen available during the thermal oxidation. The $\mathrm{x}$-ray diffraction peaks were indexed as (100), (002), (101), (102), (110) and (103), which corresponded to hexagonal $\mathrm{ZnO}$ crystals, based on the PDF x-ay diffraction card No 36-1451. Beyond these peaks, a peak indexed as the (040) plane of orthorhombic $\mathrm{PbO}$ based on the x-ray diffraction PDF card no. 80-1917 were also noted. This means that the zinc oxide $(\mathrm{ZnO})$ is the continuous phase formed on the oxide layer. However, in the limited amount of oxygen in the $\mathrm{N}_{2} / 5$ wt. $\%$ gaseous atmosphere, the continuity of the $\mathrm{ZnO}$ was affected, suggesting that some limited amount of lead (II) oxide ( $\mathrm{PbO}$ ) were present on the surfaces, hence their diffraction of the $\mathrm{x}$-ray beams. As the amount of $\mathrm{O}_{2}$ increased, the $\mathrm{ZnO}$ layer increased in thickness and covered the limited amount of $\mathrm{PbO}$ present as can be seen in the diminishing intensities and number of diffraction peaks for $\mathrm{PbO}$ in $\mathrm{x}$-ray diffraction patterns recorded for the alloy samples oxidized in $\mathrm{N}_{2}-12 \mathrm{wt}$. $\%$ gaseous atmosphere. Furthermore, this chemical composition of the oxide layer, established through the $\mathrm{x}$-ray diffraction studies can be justified thermodynamically. Using a combination of thermodynamic relationships stated in 4-721,22, the standard Gibb's Free energy change values ( $\Delta \mathrm{G}_{\mathrm{T}}^{\mathrm{o}}$ ) for the reactions 1-3 were calculated.

$$
\begin{aligned}
& P b_{(l)}+\frac{1}{2} \mathrm{O}_{2(g)} \rightarrow \mathrm{PbO}_{2(s)} \\
& \mathrm{Cu}_{(s)}+\frac{1}{2} \mathrm{O}_{2(g)} \rightarrow \mathrm{CuO}(s)
\end{aligned}
$$
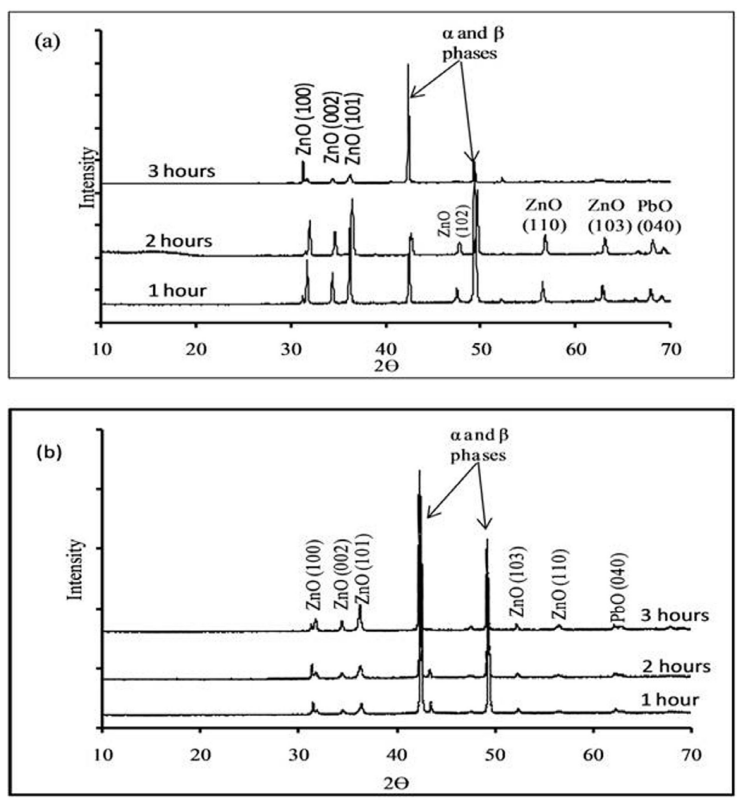

Figure 2. x-ray diffraction peaks for the oxide layer formed on the thermal oxidation of $\mathrm{Cu}-32.02 \% \mathrm{Zn}-2.30 \% \mathrm{~Pb}$ alloy for 1,2 and 3 hours in (a) $\mathrm{N}_{2}-5$ wt. $\% \mathrm{O}_{2}$ and (b) $\mathrm{N} 2-12$ wt. $\% \mathrm{O}_{2}$.
$Z n_{(s)}+\frac{1}{2} O_{2(g)} \rightarrow Z n O_{(s)}$

$\Delta \mathrm{G}_{\mathrm{T}}^{\mathrm{o}}=\Delta \mathrm{H}_{\mathrm{T}}^{\mathrm{o}}-\mathrm{T} \Delta \mathrm{S}_{\mathrm{T}}^{\mathrm{o}}$

$\left(\frac{d \Delta H^{o}}{d T}\right)=\Delta a+\Delta b T+\Delta c T^{-2}$

$\frac{\mathrm{d}\left(\frac{\Delta \mathrm{G}_{\mathrm{T}}^{\mathrm{o}}}{\mathrm{T}}\right)}{\mathrm{dT}}=\frac{-\Delta \mathrm{H}_{\mathrm{T}}^{0}}{\mathrm{~T}^{2}}=\frac{-\Delta \mathrm{H}_{\mathrm{o}}}{\mathrm{T}^{2}}-\frac{\Delta \mathrm{a}}{\mathrm{T}}-\frac{\Delta \mathrm{b}}{2}+\frac{\Delta \mathrm{C}}{\mathrm{T}^{3}}$

$\Delta G_{T}^{0}=I T+\Delta H_{0}-\frac{\Delta b T^{2}}{2}-\frac{\Delta C}{2 T^{2}}$

Using known values for the thermodynamic parameters a, $\mathrm{b}$ and $\mathrm{c}$, from thermodynamic tables, the Gibbs Free energies $\left(\Delta G_{T}^{0}\right)$ at $650^{\circ} \mathrm{C}$, which the thermal oxidation was carried out were calculated ${ }^{23}$. For reactionss (1), (2) and (3), $\Delta G_{T}^{0}$ so determined at the $650{ }^{\circ} \mathrm{C}$ were $-150.07 \mathrm{~kJ}$ and $-299.57 \mathrm{~kJ}$; $-358.54 \mathrm{KJ}$ and $-584.18 \mathrm{~kJ}$ respectively. The values of the calculated $\Delta G_{T}^{0}$ at $650{ }^{\circ} \mathrm{C}$ shows that the formtion of the zinc (II) oxide was most likely or most feasible due to the more negative Gibbs free energy value, agreeing totally with the results of the $\mathrm{x}$-ray diffraction analyses.

\subsection{Effect of the amount of oxygen and time on the oxide morphology}

The morphology of the oxides formed on the oxide layer was found to depend on the amount of oxygen available during the thermal oxidation and on the time used for the process. The morphology of the oxides on the surface layers of the $\mathrm{Cu}-32.02 \% \mathrm{Zn}-2.30 \% \mathrm{~Pb}$ alloy samples that were thermally oxidized in the $\mathrm{N}_{2}-5 \mathrm{wt} . \% \mathrm{O}_{2}$ atmosphere showed variations from those observed on samples that were oxidized on $\mathrm{N}_{2}-$ 12 wt. $\% \mathrm{O}_{2}$ gaseous atmosphere.

The morphologies of the oxides showed randomly growing nanowires, previously confirmed as consisting of $\mathrm{ZnO}$. In the $\mathrm{N}_{2}-5.0 \mathrm{wt} . \% \mathrm{O}_{2}$ atmosphere, the average diameter, average length as well as the average distances between the observed nanowires were $27 \pm 0.01 \mathrm{~nm}, 0.20 \pm 0.04 \mu \mathrm{m}$ and $0.20 \pm 0.04 \mu \mathrm{m}$ respectively. However, when the amount of oxygen was increased to $12 \mathrm{wt} . \%$, the oxide morphologies showed randomly growing nanowires previously confirmed as consisting of $\mathrm{ZnO}$. In the $\mathrm{N}_{2}-5.0$ wt. $\% \mathrm{O}_{2}$ atmosphere, the average diameter, average length as well as the average distances between the observed nanowires were $27 \pm 0.01 \mathrm{~nm}$, $0.20 \pm 0.04 \mu \mathrm{m}$ and $0.20 \pm 0.04 \mu \mathrm{m}$ respectively. However, when the amount of oxygen was increased to $12 \mathrm{wt} . \%$, the average diameters equally increased in values in response to the increase in the amount of oxygen in the oxidizing atmosphere.

On the other hand, the density of the nanowires per unit area of the surfaces reduced drastically. This confirms that the amount of oxygen is a determinant parameter that influences the length, the diameter and the density of nanowires grown via the thermal oxidation route ${ }^{24}$. Beyond the above, the oxide scale showed severe distortion. This can be seen in Figures 3 and 4. This distortion of the oxide layer is essentially due to the difference in the thermal expansivity 

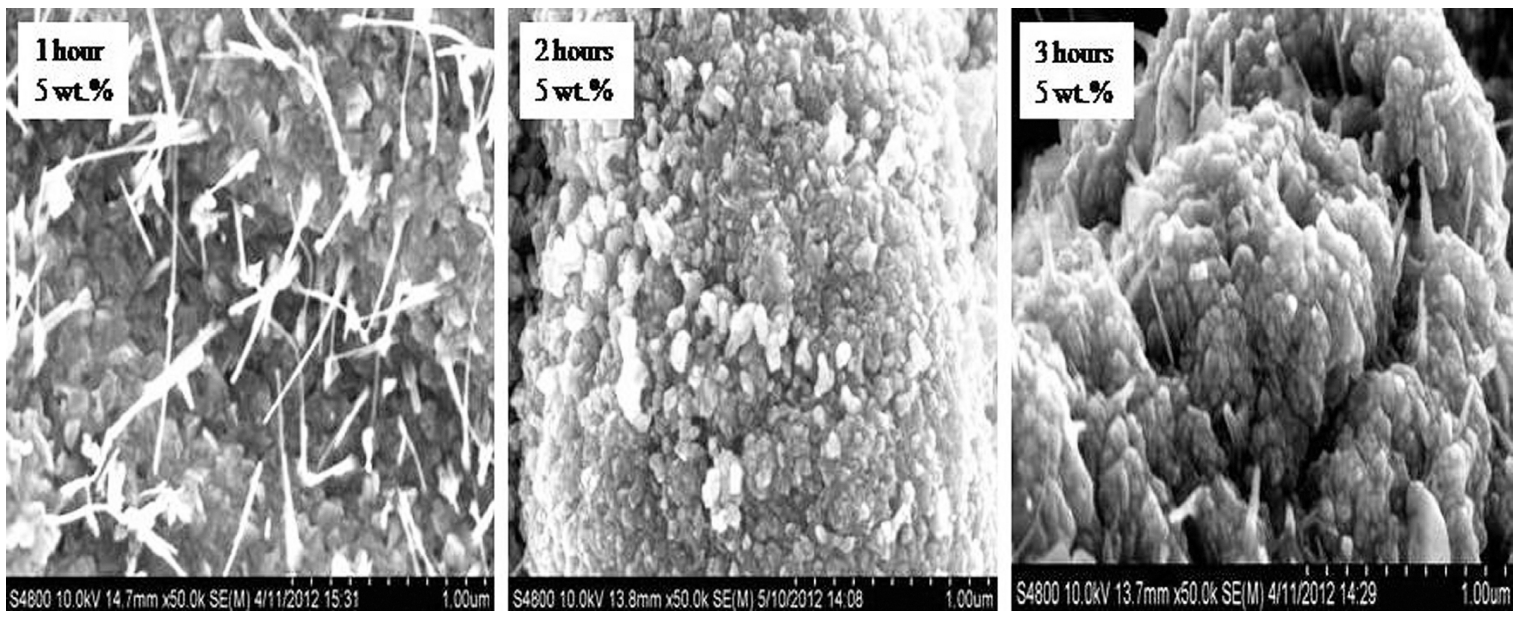

Figure 3. SEM images of oxide morphology on thermal oxidation of $\mathrm{Cu}-32.02 \% \mathrm{Zn}-2.30 \% \mathrm{~Pb}$ alloy in $\mathrm{N}_{2}-5$ wt. $\% \mathrm{O}_{2}$ for 1.2 and 3 hours.


Figure 4. SEM images of oxide morphology on thermal oxidation of $\mathrm{Cu}-32.02 \% \mathrm{Zn}-2.30 \% \mathrm{~Pb}$ alloy in $\mathrm{N}_{2}-12$ wt. $\% \mathrm{O}_{2}$ for 1.2 and 3 hours.

of the alloy and the oxides and compressive stresses due to other crystallographic factors. These crystallographic factors are expressed in the Pilling-Bed worth ratio (PBR), stated in (8) which relates the ratio of the volume of the oxide formed during the thermal oxidation to the volume of the consumed alloy or metal and is expressed as:

$\frac{\mathrm{A}_{\mathrm{o}} \rho_{\mathrm{M}}}{\mathrm{A}_{\mathrm{M}} \rho_{\mathrm{o}}}=\mathrm{PBR}$

where $A_{o}$ and are the molecular weights of $\mathrm{ZnO}$ and the $\mathrm{Zn}$ species while $\rho_{\mathrm{O}}$ and $\rho_{\mathrm{M}}$ are their densities respectively. It is expected that when the PBR is less than one $(\mathrm{PBR}<1)$, the oxide layer will be very thin and less likely to get broken; when the PBR is greater than one but less tha two $(1<$ PBR $<2)$, the oxide layer formed will be closed with a certain level of compressive stresses within, capable of setting off the growth of metal oxide nanostructures ${ }^{25}$.

The $\mathrm{P}-\mathrm{B}$ ratio was calculated for the $\mathrm{ZnO}$, which the continuous oxide phase as noted from the EDX and XRD studies. The value of 1.58 was obtained implying that the oxide layer had compressive stresses within it that was sufficient to cause the growth of the $\mathrm{ZnO}$ nanowires. Therefore, the $\mathrm{ZnO}$ nanowires growth on the thermally oxidized $\mathrm{Cu}-32.02 \%$ $\mathrm{Zn}-2.30 \% \mathrm{~Pb}$ alloy is a function of the compressive stresses generated within the oxide layers. In terms of the effect of time on the morphology of the oxides formed, it was noted that nanowire growth was only observed within the first one (1) hour of the thermal oxidation. After two (2) and threee (3) hours of the thermal oxidation, no nanowires were observed on the oxide layer. However, the oxide layers in these cases consisted of oxide granules of various forms, with fairly regular shapes as can be seen in Figures 3 and 4 .

\subsection{Growth kinetics of the oxide layer}

The growth kinetics of the oxide layer was explored by using the values obtained for its average thickness. These values of the average thickness of the oxide layer are as stated in Table 1.

Oxide growth commonly follow the linear or the parabolic growth models ${ }^{26,27}$. For the linear growth model, the oxide layer thickness increases linearly with time, implying that the oxygen ions passes right through the fissures in the oxide 
Table 1. Table showing the oxide layer thickness for the various durations of thermal oxidation of $\mathrm{Cu}-32.02 \% \mathrm{Zn}-2.30 \% \mathrm{~Pb}$ in various oxidzing atmospheres.

\begin{tabular}{ccc}
\hline \multirow{2}{*}{$\begin{array}{c}\text { Oxidizing } \\
\text { atmosphere at } \\
650{ }^{\circ} \mathrm{C}\end{array}$} & $\begin{array}{c}\text { Time of Oxidation } \\
\text { (hours) }\end{array}$ & $\begin{array}{c}\text { Oxide layer } \\
\text { Thickness at } 650{ }^{\circ} \mathrm{C} \\
\text { (in microns) }\end{array}$ \\
\hline \multirow{2}{*}{$\mathrm{N}_{2}-5$ wt. \% $\mathrm{O}_{2}$} & 1 & $6.54 \pm 2.36$ \\
\cline { 2 - 3 } & 2 & $9.99 \pm 3.58$ \\
\hline & 3 & $22.9 \pm 5.86$ \\
\hline $\mathrm{N}_{2}-12.00$ wt. $\% \mathrm{O}_{2}$ & 1 & $21.86 \pm 1.23$ \\
\cline { 2 - 3 } & 2 & $36.06 \pm 6.15$ \\
\hline
\end{tabular}

layer to react on the metal surface for the oxidation to occur. The linear growth rate is represented according to:

$$
X=K_{l} t
$$

For the parabolic model on the other hand, the oxide layer is sufficiently thick and diffusion of oxygen ions must occur for additional growth of the layer. The parabolic growth rate is given as:

$$
x^{2}=K_{P} t
$$

In the relationships stated in (9) and (10), $\mathrm{X}$ is the oxide layer thickness, $K_{l}=$ linear rate constant, $K_{p}=$ parabolic rate constant and $\mathrm{t}=$ thermal oxidation time.

To determine the applicable model for the kinetics of the growth of the oxide layer observed on the thermal oxidation of the $\mathrm{Cu}-32.02 \% \mathrm{Zn}-2.30 \% \mathrm{~Pb}$ alloy, we applied the regression analysis through the evaluation of the coefficient of determination, $\mathrm{R}^{2}$. To this end, the variation of the oxide layer thickness against time was determined by the plots of the oxide layer thickness (X) against thermal oxidation time and the oxide layer thickness against the square root of the thermal oxidation time, for the linear and the parabolic growth models respectively.

These plots, in Figure 5 and in Figure 6, are based on the linear and parabolic oxide growth models respectively. For the linear model,represented in Figure 5, the $\mathrm{R}^{2}$ values of 0.935 and 0.783 were obtained for the alloy samples thermally oxidized in $\mathrm{N}_{2}-5$ wt. $\% \mathrm{O}_{2}$ and $\mathrm{N}_{2}-12$ wt. $\%$ $\mathrm{O}_{2}$ oxidizing atmospheres respectively. For the parabolic model, represented in Figure 6 , the $\mathrm{R}^{2}$ values of 0.854 and 0.980 were equally obtained for the samples of the alloy that were thermally oxidized in $\mathrm{N}_{2}-5$ wt. $\% \mathrm{O}_{2}$ and $\mathrm{N}_{2}-12$ wt.\% $\mathrm{O}_{2}$ oxidizing atmospheres respectively. The $\mathrm{R}^{2}$ value of 0.935 shows that the oxide layer thickness values fitted the linear model more, for the alloy samples that were thermally oxidized in $\mathrm{N}_{2}-5 \mathrm{wt}$. \% oxygen atmosphere. On the other hand, the $\mathrm{R}^{2}$ value of 0.980 implies that the oxide layer thickness measured from the samples oxidized in $\mathrm{N}_{2}-12 \mathrm{wt}$. \% oxygen atmosphere fitted the parabolic model better. To this end, the regression analysis shows that the oxide growth in $\mathrm{N}_{2}-5 \mathrm{wt}$. $\%$ oxygen atmosphere followed the linear model while in $\mathrm{N}_{2}-12$ wt. \% oxygen atmosphere, the oxide growth followed the parabolic model. models for the alloy samples that were thermally oxidized in $\mathrm{N}_{2}-5 \mathrm{wt}$. \% oxygen atmosphere and $\mathrm{N}_{2}-12 \mathrm{wt} \%$ oxygen atmosphere. The values of $6.8 \mu \mathrm{m} /$ hour and $23.03 \mu \mathrm{m} /(\text { hour })^{1 / 2}$ were determined for $\mathrm{K}$ in both cases.

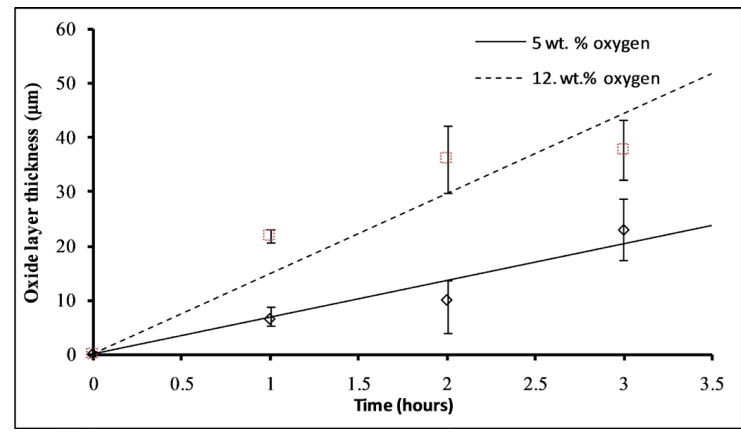

Figure 5. Variation of the oxide layer thickness $(\mu \mathrm{m})$ with the time (hours) based on the linear model for $\mathrm{Cu}-32.02 \% \mathrm{Zn}-2.30 \% \mathrm{~Pb}$ alloy that is thermally oxidized in $\mathrm{N}_{2}-5$ wt. $\% \mathrm{O}_{2}$ atmosphere and $\mathrm{N}_{2}-12$ wt. $\% \mathrm{O}_{2}$ atmosphere respectively.



Figure 6.Variation of the oxide layer thickness $(\mu \mathrm{m})$ with the time (hours) based on the parabolic model for $\mathrm{Cu}-32.02 \% \mathrm{Zn}-2.30 \% \mathrm{~Pb}$ alloy that is thermally oxidized in $\mathrm{N}_{2}-5 \mathrm{wt} . \% \mathrm{O}_{2}$ atmosphere and $\mathrm{N}_{2}-12$ wt. $\% \mathrm{O}_{2}$ atmosphere respectively.

This shows that the oxide grew much faster in the atmosphere with high oxygen content, even though at later stages of the oxide growth, the process slowed down, limited by the diffusion of oxygen ions through the thickened oxide layer.

\section{Conclusion}

In conclusion, the high temperature thermal oxidation of the $\mathrm{Cu}-32.02 \% \mathrm{Zn}-2.30 \% \mathrm{~Pb}$ alloy resulted in different oxide morphologies, especially nanowires which grew within specific time windows. The $\mathrm{x}$-ray diffraction and energy dispersive analyses of the oxide layer showed that they consisted of a continuous phase of Zinc (II) Oxide ( $\mathrm{ZnO}$ ). The planes of the oxides were properly indexed through appropriate Miller indices. The oxide growth kinetics followed the linear oxide growth model, for the alloy samples that were thermally oxidized in $\mathrm{N}_{2}-5 \mathrm{wt} . \% \mathrm{O}_{2}$ atmposphere and parabolic growth model for those thermally oxidized in $\mathrm{N}_{2}-12$ wt. $\% \mathrm{O}_{2}$ atmospheres respectively. The appropraite rate constant were also determined.

\section{References}

1. Wright RN. Process engineering and metallurgy. 2nd ed. UK: Butterworth-Heinemann; 2016. Chapter 13, Relevant aspects 
of copper and copper alloy metallurgy, wire technology; p. 177-200.

2. Wegman RF, Van Twisk J. Surface preparation techniques for adhesive bonding. 2nd ed. USA: Elsevier; 2013. Copper and copper alloys; p. 83-91.

3. Schultheiss F, Johansson D, Bushlya V, Ståhl J. Comparative study on the machinability of lead-free brass. J Clean Prod. 2017; 149:366-77.

4. Fadhil AA, Enab TA, Samuel M, Iskander BA, Ajeel SA. Study on the Effect of production parameters and raw materials used on the mechanical properties of leaded brass $(\mathrm{CuZn} 40 \mathrm{~Pb} 2)$ alloy, world. J Eng Technol. 2017;5:340-9.

5. Suárez L, Rodriguez-Calvillo P, Cabrera JM, Martinez-Romay A, Majuelos-Mallorquin D, Coma A. Hot working analysis of a CuZn40Pb2 brass on the monophasic $(\beta)$ and intercritical $(\alpha$ $+\beta)$ regions. Mater Sci Eng A. 2015;627:42-50.

6. Schultheiss F, Windmark C, Sjöstrand S, Rasmusson M, Ståh J. Machinability and manufacturing cost in low-lwad brass. Int J Adv Manuf Technol. 2018;99:2101-10.

7. Choopun S, Hongsith N, Wongrat E. Metal-oxide nanowires by thermal oxidation reaction technique. In: Prete $\mathrm{P}$, editor. Nanowires, United Kingdom: IntechOpen; 2010. p. 97-116.

8. Liu ZW, Zhong ML, Tang CM. Large-scale oxide nanostructures grown by thermal oxidation. IOP Conf Series: Mater Sci Eng. 2014;60(1):012022.

9. Zappa D, Bertuna A, Comini E, Kaur N, Poli N, Sberveglieri $\mathrm{V}$, et al. Metal oxide nanostructures: preparation, characterization and functional applications as chemical sensors. Beilstein J Nanotechnol. 2017;8:1205-17.

10. Lao JY, Wen JG, Ren ZF. Hierarchical ZnO nanostructures. Nano Lett. 2002;2(11):1287-91.

11. Hughes WL, Wang ZL. Controlled synthesis and manipulation of ZnO nanorings and nanobows. Appl Phys Lett. 2005;86:04310610.

12. Castrejón-Sánchez VH, Solís AC, López R, Encarnación-Gomez C, Morales FM, Vargas OS, et al. Thermal oxidation of copper over a broad temperature range: towards the formation of cupric oxide (CuO). Mater Res Express. 2019,6(7):075909.

13. Mardiansyah D, Badloe T, Triyana K, Mehmood MQ, RaeisHosseini N, Lee Y, Sabarman H, et al. Effect of temperature on the oxidation of $\mathrm{Cu}$ nanowires and development of an easy to produce, oxidation-resistant transparent conducting electrode using a PEDOT:PSS coating. Sci Rep. 2018;8:10639.

14. Mohammed HA. Some physical properties of $\mathrm{ZnO}$ thin films prepared by thermal oxidation of metallic $\mathrm{Zn}$. Optoelectron Adv Mater Rapid Commun. 2012;6(3):389-93.

15. Gao W, Li ZW, Harikisun R, Chang S. Zinc oxide films formed by oxidation of zinc under low partial pressure of oxygen. Mater Lett. 2003;57:1435-40.

16. Wang L, Zhao Y, Zheng K, She J, Deng S, Xu N, et al. Fabrication of large-area $\mathrm{ZnO}$ nanowire field emitter arrays by thermal oxidation for high-current application. Appl Surf Sci. 2019;484:966-74.

17. Zhu Y, Mimura K, Lim JW, Isshiki M, Jiang Q. Brief review of oxidation kinetics of copper at $350^{\circ} \mathrm{C}$ to $1050^{\circ} \mathrm{C}$. Metall Mater Trans, A Phys Metall Mater Sci. 2006;37:1231-7.

18. Bellakhal N, Dachraoui M. Electrochemical investigation of the oxides formedat the surface of brass $(\mathrm{Cu}-10 \mathrm{Zn})$ by a humid-air plasma treatment. Mater Chem Phys. 2003;82:484-8.

19. Bellakhal N, Draou K, Brisset JL. Plasma and wet oxidation of (63Cu37Zn)brass. Mater Chem Phys. 2002;73:235-41.

20. Saunders SRJ, Monteiro M, Rizzo F. The oxidation behaviour of metals and alloys at high temperatures in atmospheres containing water vapour: a review. Prog Mater Sci. 2008;53:775-837.

21. Atkins P, Paula JD. Physical chemistry. UK: Oxford University Press; 2014.

22. Gaskell DR, Lauughlin DE. Introduction to the thermodynamics of materials. Boca Raton: CRC Press; 2012.

23. Kubaschewski O, Alcock CB, Spencer PJ. Materials thermochemistry. UK: Pergamon Press; 1993.

24. Campos AC, Paes SC, Correa BS, Cabrera-Pasca GA, Costa $\mathrm{MS}$, Costa CS, et al. Growth of long $\mathrm{ZnO}$ nanowires with high density on the $\mathrm{ZnO}$ surface for gas sensors. ACS Appl Nano Mater. 2020;3:175-85.

25. $\mathrm{Xu} \mathrm{CH}$, Woo CH, Shi SQ. The effects of oxidation environments on the synthesis of $\mathrm{CuO}$ nanowires on $\mathrm{Cu}$ substrates. Superlattices Microstruct. 2004;36:31-8.

26. Trindade VB, Borib R, Hanjari BZ, Yang S, Krupp U, Christ H-J. High-temperature oxidation of pure fe and the ferritic steel 2.25Cr1Mo. Mater Res. 2005;8:365-9.

27. Monceau D, Pieraggi B. Determination of parabolic rate constants from a local analysis of mass-gain curves. Oxid Met. 1998;50:477-93. 